\title{
Uso de Indicadores em Pesquisas de Orientação Psicanalítica: Um Debate Conceitual ${ }^{1}$
}

\author{
Maria Cristina Machado Kupfer ${ }^{2}$ \\ Rinaldo Voltolini \\ Universidade de São Paulo
}

\begin{abstract}
RESUMO - Pretende-se, no presente trabalho, apresentar um debate em torno dos impasses teóricos e das possibilidades do uso de indicadores clínicos em pesquisas de orientação psicanalítica. $\mathrm{O}$ uso de indicadores clínicos, já consagrado na área da Saúde, mas ainda polêmico na clínica psicanalítica, pode ser reconsiderado levando em conta várias aproximações possíveis entre o modo de produzir conhecimento em psicanálise e aquele utilizado em outras ciências afins. Segue-se a essa argumentação um debate no qual se examinam as tensões existentes entre o discurso psicanalítico e o médico, não para afastá-los, mas para produzir uma articulação entre eles.
\end{abstract}

Palavras-chave: indicadores clínicos; pesquisa psicanalítica; discurso médico; saúde mental; saúde pública.

\section{The Use of Indicators in the Psychoanalytic Oriented Research: A Conceptual Discussion}

\begin{abstract}
The work aims to discuss the use of clinical indicators in researchers on psychoanalytic orientation. The use of those indicators in the health field is already well stablished, but it is unusual in the psychoanalytical research. Nevertheless, it is possible to put together, in some aspects, the way of producing knowledge in psychoanalysis and the way used by similar sciences. Based on the idea previously exposed, the examination of the existing tensions created between the psychoanalytical and medical speeches, not separating them, but producing an articulation of the two fields is discussed.
\end{abstract}

Key words: clinical indicators; psychoanalytical research; medical speech; mental health; public health.

Em 2000, iniciou-se, a pedido do Ministério da Saúde e com o apoio, a partir de 2004, também da Fundação de Apoio à Pesquisa do Estado de São Paulo (Fapesp), uma pesquisa para a validação de indicadores clínicos de risco para o desenvolvimento infantil. O pressuposto é que esses indicadores clínicos podem ser empregados por pediatras e por outros profissionais de saúde da atenção básica em consultas regulares e podem ser úteis para indicar a possibilidade de ocorrerem ulteriormente transtornos psíquicos do desenvolvimento infantil. O estudo trabalha com uma amostra de 700 crianças atendidas em nove cidades brasileiras e já se encontra na fase em que as crianças, tendo atingido 3 anos, serão submetidas a um diagnóstico para verificar o valor preditivo dos indicadores.

Existe um desafio contido nessa pesquisa: o de que se pode trabalhar com indicadores construídos a partir da teoria psicanalítica. De fato, não há consenso em torno da possibilidade de uso de medidas e tampouco em torno da construção de protocolos clínicos que utilizem indicadores clínicos objetivos com base na psicanálise. Assim, a pesquisa em questão situa-se em um campo no qual as discordâncias têm sido levantadas de modo vigoroso.

1 Apoio financeiro: FAPESP, CNPq e Ministério da Saúde. Trabalho apresentado no Colóquio franco-brasileiro "Clinique des bébés: le support de la recherche", em Paris, em janeiro de 2005.

2 Endereço: Rua Heitor de Andrade, 40, São Paulo, SP, Brasil 05441-020. E-mail: mckupfer@usp.br
O presente trabalho é o resultado de um debate, em que se apresenta, primeiramente e de forma breve, a pesquisa em curso, bem como os argumentos teóricos utilizados para justificar o emprego de indicadores clínicos em sua metodologia. Em seguida, contrapõe-se a essa apresentação uma reflexão sobre os impasses teórico-epistemológicos que se enfrentam no encontro da psicanálise com a medicina.

\section{A pesquisa e seus fundamentos teórico-metodológicos}

O uso de indicadores clínicos nas pesquisas da área da saúde já está consagrado (Brunelle \& Saucier, 1999; Almeida Filho, 1989), mas é estranho à pesquisa de orientação psicanalítica. Atualmente, porém, essa situação está sofrendo modificações, principalmente entre os pesquisadores que vêm se dedicando à pesquisa psicanalítica na universidade. Se há ainda uma tendência de afirmar uma especificidade científica da psicanálise, pondo-a à parte da produção científica universitária, tem havido, de outro lado, uma tentativa de fazê-la participar do diálogo com a ciência positiva, sem, é claro, escamotear as diferenças. Na produção desse diálogo, reconhecem-se semelhanças entre o modus operandi de produção de conhecimento em psicanálise e aquele utilizado em outras ciências afins.

Assim, há autores, como Hanns (2000), Mezan (2002), Pereira (2001), Vieira (2001) e Garcia (2002), para os quais é possível considerar a psicanálise como uma ciência que participa do campo das ciências humanas, bem como construir instrumentos de medida nela apoiados. 
Hanns (2000) afirma, muito justamente, que a psicanálise não pertence ao campo da medicina, mas aproxima-se muito mais, em termos metodológicos, do campo da economia, e pode compor com ela, dentro de um conjunto do qual participam outras ciências, um campo que propõe chamar de "dinâmico-tendencial". Tal denominação justifica-se pelo fato de a psicanálise constituir, segundo esse autor, um campo que lida com muitas variáveis - dinâmico, portanto -, cuja articulação permite, se não fazer previsões exatas, pelo menos destacar tendências - por isto, tendencial. Nessa direção, torna-se possível buscar medidas objetivas de aspectos estruturais.

O grupo de experts que idealizou a pesquisa e construiu os indicadores justifica esse uso a partir da constatação de que a presença de um sujeito psíquico só pode ser verificada com base nos efeitos indiretos que ela produz. Assim, a leitura dessa presença de sujeito precisa apoiar-se em sinais fenomênicos que permitam supô-la. Esses sinais podem ser traduzidos em termos de indicadores, a partir dos quais é possível supor como está ocorrendo a instalação de um sujeito, bem como articular essa constituição com o plano do desenvolvimento da criança (Kupfer \& cols., 2003).

Os indicadores foram construídos com a utilização de eixos teóricos definidos a partir de um modo de conceber a constituição do sujeito. Para cada eixo, há indicadores fenomênicos que o exemplificam e especificam.

Os eixos foram construídos com base no conhecimento teórico-clínico já construído pela psicanálise sobre as diferentes operações psíquicas que se estabelecem na primeira infância. Tendo como parâmetro inicial o que entra em jogo no laço entre mãe e filho, destacaram-se observações significativas dos diferentes tempos, nos quais está em jogo a construção da imagem corporal, do circuito pulsional e da inscrição simbólica, para determinar o que seria esperado em cada período da constituição do sujeito.

A metodologia utilizada no estabelecimento dos indicadores é a da consulta a experts, a exemplo do que já se pratica em pesquisas da área de saúde (ver, por exemplo, Ministère de la Santé et des Services Sociaux du Québec, 1996, citado em Brunelle \& Saucier, 1999). Coube ao grupo de experts recolher, dentre as observações significativas mencionadas, aqueles indicadores já comumente utilizados no cotidiano da clínica psicanalítica com crianças e bebês e que apresentam, por sua ocorrência freqüente e pela casuística com que aparecem, uma plausibilidade clínica, relativa simplicidade de leitura, operacionalidade e transmissibilidade clínica. Construiu-se um conjunto de índices cuja ausência poderá apontar para a existência de perturbações no desenrolar do diálogo mãe-bebê.

Nessa discussão, percebe-se que o indicador é como um signo que se relaciona com os demais numa rede discursiva ou em uma lógica simbólica, cuja leitura baseia-se nos eixos teóricos em torno dos quais eles foram construídos. Assim, deve-se lembrar que os indicadores, separadamente, não indicam nada. Precisam estar relacionados entre si para que possam apontar a lógica do eixo em torno do qual estão articulados.

Neste ponto da argumentação, é possível supor uma objeção a ser levantada: como articular uma proposta de utilização de indicadores com o pressuposto psicanalítico segundo o qual não existe prevenção de transtornos psicopatológicos? De acordo com a psicanálise, aquilo que faz marca para um sujeito pode não o fazer para outro, ou seja, a ausência de um indicador em um bebê não significaria necessariamente determinada evolução psicopatológica ulterior. A lógica psicanalítica não opera segundo o modelo de causa e efeito, ou seja, a ausência do olhar materno não poderá ser pensada como causa cujo efeito seria o autismo.

A essa objeção, Jerusalinsky (s./d.) responde apoiando-se em uma outra lógica que poderia fundamentar o estabelecimento de indicadores. Para esse autor, a lógica que preside à leitura do sujeito na psicanálise é a do acontecimento e suas consequiências.

Em se tratando de acontecimentos, eles carregam uma significação subjetiva que o conceito de causa não possui. E a substituição do termo 'efeito' pelo termo 'conseqüencia' implica que se determina, nesse ponto, a abertura de uma nova experiência para o sujeito em questão (p. 1).

A argumentação de Jerusalinsky não resolve, contudo, a objeção apresentada, pois, de qualquer modo, o acontecimento é sempre de natureza subjetiva, e portanto inapreensível, e suas consequiências só poderiam ser percebidas em um momento sempre posterior, ou seja, sempre no "après coup", que viria, além disso, ressignificar necessariamente o acontecimento. Como conciliar essa visão e o uso de indicadores?

Aqui é preciso apontar um outro aspecto dessa pesquisa. Trata-se do esforço de fazer a experiência acumulada da psicanálise ser levada à saúde pública. O psicanalista não precisa de um formulário com indicadores, mas o pediatra sim. Por isso, o que está sendo transmitido é uma tendência geral, que pode ser desenhada, riscada em um gráfico, tendência essa obtida a partir da experiência do psicanalista. Se uma mãe não olha para seu bebê, não se sabe qual a marca que isso lhe fará, mas é possível pensar que, tendencialmente, o diálogo pais-bebê está correndo o risco de interromper-se. Como será esse vivido, não o sabemos, mas podemos fazer um cálculo futuro, sem que isso signifique previsão.

$\mathrm{O}$ desafio com que estamos nos ocupando consiste em articular caso a caso e a ciência geral. A psicanálise já tem elementos para fazer essa articulação no interior da clínica: trata-se de articular a estrutura com a versão que cada sujeito constrói ao atravessá-la. Uma coisa é o Édipo como estrutura, outra coisa é a versão de cada um ao atravessá-lo (Pommier, 1989). Quando construímos indicadores, estamos mais do lado do geral da estrutura do que da versão do sujeito. Estamos aproveitando a experiência acumulada da psicanálise a fim de levá-la aos outros campos, apontando para uma tendência que vimos revelar-se ao ouvir cada caso. Estamos nos valendo do conhecimento da estatística para afirmar que algo pode acontecer com aquele sujeito porque já aconteceu, em um nível significativo, com muitos outros, e assim pedir àquele agente de saúde que leve essa tendência em conta. Não é uma pesquisa para ampliar os horizontes da psicanálise, não é uma pesquisa em psicanálise, e sim uma pesquisa de psicanálise aplicada que poderá reverter secundariamente em benefício da psicanálise, ao balançar, por exemplo, algumas certezas das quais nós partimos quando estabelecemos nossos 
indicadores com base em pressupostos já consagrados pela psicanálise.

O risco está em que os pediatras tomem esse geral estrutural que organiza os indicadores como mais uma teoria de classificação de comportamentos, como mais uma teoria geral sem articulação com a versão do sujeito, e passe a aplicá-la como se tivesse valor preditivo. O risco é que eles tomem os indicadores em uma relação de causa e efeito, e não em uma relação de acontecimento com conseqüências, porque aí cessa a verdadeira novidade da psicanálise, e ela passa a funcionar como mais uma teoria, entre muitas. Esse risco é assumido em nossa pesquisa: na relação custo/benefício, o benefício está sendo maior. Se a psicanálise for tomada como uma teoria entre outras, arranha-se a novidade da psicanálise. Se, porém, o pediatra tomar os indicadores como devem ser tomados, ou seja, apenas como aquilo que indica alguma coisa a respeito de um sujeito, então a saúde pública poderá ser beneficiada.

Caberá a esse projeto, como um todo, construir as bases para uma metodologia de base psicanalítica que permita a utilização desse conhecimento em situações externas ao tratamento-padrão. Nessa proposta, há pelo menos duas apostas: a primeira é que é possível transmitir a não-psicanalistas uma compreensão dos princípios gerais da psicanálise que resulte em uma prática modificada por essa compreensão, e, em segundo lugar, a aposta de que a psicanálise já acumulou saber suficiente para ler em alguns sinais fenomênicos a expressão de que estão em instalação processos ou estruturações de ordem psíquica. A tradução em indicadores objetivos quer da constituição do sujeito, quer do tratamento psicanalítico poderá ser auxiliar poderoso em um diálogo mais efetivo com a medicina, com a saúde pública e com a cultura de nosso tempo.

\section{Impasses no encontro da psicanálise com a medicina}

Construir uma metodologia de base psicanalítica capaz de permitir que algo da psicanálise transmita-se a outras práticas que se deixem influenciar por ela é uma tarefa delicada. Neste sentido, os riscos acima apontados, especialmente os que se referem a como os indicadores podem vir a ser utilizados no meio médico, não o são sem motivo. Já demonstram uma via de tradução (de uma língua psicanalítica para outra, médica) conhecida e tendem, em geral, a diminuir o peso das diferenças entre essas formas de saber.

Concebemos, contudo, que é no exame dessas diferenças entre os campos da psicanálise e da medicina que alguma articulação será possível, sem cairmos ora no obscurantismo para fins pragmáticos, ora no isolamento dogmático típico do campo religioso, que se define pelo empenho do crente na reafirmação de suas certezas, bloqueando o acesso à verdade.

Se escolhemos tratar a questão dos indicadores pelo viés metodológico, isso não quer dizer que este seja o único campo de discussão, apenas indica um ponto de partida. Com efeito, se a posição metodológica da psicanálise pôde surgir como novidade em relação à medicina, isto se deu porque Freud soube ocupar outra "posição discursiva", o que consistiu basicamente em deslocar-se do "auscultar" para o "escutar". A partir desse deslizamento de posição, fundante de um novo tipo de laço social, Freud encaminhará sua pesquisa e conduzirá os tratamentos de seus pacientes.
Trata-se, pois, de considerar essa intersecção entre psicanálise, medicina, psicologia e educação, levando em conta as "economias discursivas" em jogo, já que é nelas que podemos falar de "efeitos", sem nos perdermos num debate estritamente epistemológico, tendente à esterilidade. Basta lembrarmos, sobre isso, a observação de Freud, em seu escrito "Psicanálise "silvestre" (1910/1980), a respeito do uso "distorcido" de um conceito psicanalítico feito por um médico "não analista".

Deveríamos entender essa distorção como um problema de compreensão conceitual somente? Freud teria dado relevância a esse fato, se ele fosse tão contingente assim? Ou, antes, poderíamos supor que, se Freud dá relevância a esse episódio, estaria apontando para um risco da transmissão da psicanálise, especialmente quando ela envolve o discurso médico e suas linhas de força? Quando um médico "prescreve", ainda que se valendo "erradamente" de um conceito psicanalítico, não o faz de modo aleatório. Aliás, seguindo minimamente a lição de Freud sobre os atos falhos, podemos, nesse caso, pensar que as distorções de compreensão são reveladoras.

Pois bem, o debate estritamente epistemológico serviria para esclarecer os termos da distorção, elucidar o conceito em questão, mas não ajudaria a compreender a posição de gozo que concerne a essa distorção. Com efeito, é esse mesmo tipo de fato que fez Lacan (1969-70) observar que "os lugares pré-interpretam", ou seja, que é na economia discursiva que se definem o sentido e o efeito de tudo o que se joga dentro dela. No que diz respeito ao campo epistemológico, Freud não via oposição entre psicanálise e psiquiatria, por exemplo. Achava que a relação entre ambas podia ser de complementaridade. Mas é a diferença entre o epistemológico e o discursivo que permite a Quinet (2001) afirmar que " $a$ psicanálise, portanto, não se opõe à psiquiatria, mas sim a todo discurso que suprime a função do sujeito" (p. 20). Ou seja, quando a questão é obter efeitos sobre uma outra prática, considerar a economia discursiva é uma forma de levar em conta que, em qualquer discussão envolvendo dois campos epistemologicamente distintos, não são só idéias "claras e distintas" que estão em jogo. E significa, sobretudo, observar que um discurso não se ordena a partir da razão, mas, antes, de maneira "sobredeterminada" pelo gozo.

A abordagem das tensões discursivas, entretanto, não implica assinalar uma impossibilidade de interlocução. Isso seria admitir que os vários discursos que se ordenam numa dada sociedade poderiam ser reduzidos, de modo simples, aos quatro discursos elaborados por Lacan. Mais ainda, seria admitir que os discursos funcionam estaticamente, e não basculam de modo que se possa passar de um para outro.

A aproximação entre dois discursos distintos como o da psicanálise e o da medicina comporta dois lados, como salienta Monseny (2001): 1) é o mesmo real que está em jogo e 2) o real em jogo na clínica não é indiferente ao discurso que o apreende. Levando em conta esses dois lados, passaremos em seguida a examinar alguns pontos difíceis na comparação entre os dois discursos.

\section{O acesso ao visível e ao "pré-visível"}

Foi por meio de Foucault (1994) que pudemos ter clareza a respeito do grau em que o nascimento da clínica médica, 
tal como hoje a conhecemos, esteve atrelado à possibilidade de observação do cadáver. Isso possibilitou o "acesso ao visível", tão caro à elaboração do discurso médico, de tal modo que a maior parte dos progressos da intervenção médica sobre as doenças deve-se ao avanço tecnológico que permitiu "ver melhor".

Além de possibilitar um rompimento com o obscurantismo religioso, a observação do cadáver tornou possível também tomar o corpo como "objeto" de estudo, objetiválo, exatamente quando se pôde supor que ali "não havia um sujeito". Ou seja, o nascimento da anatomia patológica, base da medicina científica, deu-se graças ao estudo de alguém "mudo e transparente". Era mudo não apenas porque, como cadáver, obviamente não podia falar, mas principalmente porque o importante era "observar" a lesão que explicaria, justificaria os sintomas. E era transparente porque, esperavase, toda e qualquer opacidade da doença seria, por princípio, redutível. E essa condição de mudez e transparência, no entanto, não se restringe à contingência do estudo sobre o cadáver, mas sim define um dos eixos do ato médico.

A clínica médica, ordinariamente, não pode senão guiarse por aquilo que o médico consegue observar objetivamente, aquilo que o exame clínico ou laboratorial deixa transparecer. Não pode jamais guiar-se pela leitura que o próprio doente faz de sua doença, uma vez que este se equivoca, ou mesmo pode não a perceber (como no caso do estágio assintomático de algumas doenças). O "bom doente" será aquele, então, que não só permite, como facilita o "acesso ao visível", que possibilita a "objetivação" de sua doença, não importunando o médico com questões subjetivas (da ordem de seu gozo), sempre vistas como um obstáculo ao trabalho. O médico, seja ele mais ou menos humanista, pode apenas "tolerar" a subjetividade de seus pacientes, já que ela dificulta a boa observação.

Nunca é demais lembrar o incômodo gerado no discurso médico pelas histéricas com seus sintomas migratórios e sem correspondência orgânica, o que fazia, com bastante freqüência, que elas ouvissem o famoso "você não tem nada". Incômodo que provinha da opacidade de sua doença, doença esta que não deixou de aparecer aos médicos como "forjada pelo próprio sujeito". A questão é que esse "forjar pelo próprio sujeito" não ganhou para os médicos estatuto teórico, como ocorreu a Freud, por exemplo. A medicina, ao deparar com isso, escolheu rechaçar de seu discurso o sofrimento histérico (o "você não tem nada", nada de inscritível no discurso médico). E não o fez por imperícia, mas por princípio, por necessidade de funcionamento de uma economia discursiva. Como diz Clavreul (1983), para instaurar o discurso médico, “(...) é preciso, para que esse discurso se estabeleça, privilegiar certos fatos e afastar o que vai contra esse discurso" (p. 80). "Você não tem nada" é diferente de "nós não sabemos o que você tem". Para o discurso médico, não há problema em responder que se ignoram as causas de uma doença; embora isso possa prejudicar o prestígio médico, não chega a ameaçar sua economia discursiva. Mas, quando se diz que alguém não tem nada, é para afastar a ameaça à economia discursiva.

Aqui já reunimos elementos suficientes para demonstrar no que o funcionamento do discurso médico guarda relação com o "discurso do mestre". "Objetivar" é uma operação crucial para o discurso do mestre, o que implica reduzir ou eliminar o que houver de "subjetivo". A começar pela redução da polissemia característica da língua, quando se cria uma terminologia técnica, precisa, sem ambigüidades, que acaba por se restringir aos médicos. Tornar objetivo, dar consistência e realidade a um objeto, é uma operação "avessa" à da psicanálise, que, por sua vez, evidencia justamente a "pouca realidade" do objeto. Se, para o mestre, trata-se de objetivar, para o psicanalista trata-se de subjetivar.

A passagem inventada por Freud da ausculta para a escuta não representou uma mudança de instrumento de observação, mas, antes, uma mudança da postura de observação para a de interpretação, do visível para o audível, da constatação para a construção. Na clínica médica, o instante de ver, o tempo de compreender e o momento de concluir coincidem num mesmo ato, ou seja, essa é uma clínica da constatação. Exceto nos casos em que o médico se deixa interrogar por algum sintoma que "não encaixa", o que o levaria à posição descrita por Lacan como a do discurso da histérica. A lógica do "acesso ao visível" é a mesma que permite conceber o "pré-visível".

Com efeito, quando a medicina conseguiu "ver antes" que o doente sua doença, ocorreu uma mudança significativa. $\mathrm{O}$ diagnóstico desamarra-se da percepção do paciente, já que existem doenças ou estágios delas que são "silenciosos". Aqui também, de maneira exemplar, temos um outro modo de exclusão do sujeito. Pode-se perceber que cada vez mais a prática médica torna-se interventiva, atacando a doença tão logo ela dê seus primeiros sinais, só perceptíveis aos aparelhos tecnológicos concebidos por ela, e isso é possível porque a doença vai se tornando, a cada instante, mais da medicina e menos do paciente. Isso não demorou a ser percebido por muitos, que buscaram então "humanizar" a medicina, expressão por si só suspeita, na medida em que indica o caráter reformista desse empreendimento: se a questão do sujeito deve ser lembrada aos médicos, é porque não está contida na estrutura de seu ato. Como diz Clavreul (1983):

\begin{abstract}
"Não é senão num outro discurso que essa questão pode ser retomada, o que faz a psicanálise. Para ela não se trata de pretender preencher com seu saber as ignorâncias da medicina, como se elas fossem fortuitas. Pois não são ignorâncias, mas desconhecimentos, isto é, elas são sistemáticas e estruturantes para a construção do discurso médico. São, portanto, obstáculos epistemológicos que marcam os limites do saber e do poder médico, como marcam alhures os limites do discurso psicanalítico” (p. 34).
\end{abstract}

\section{Saúde pública: governar}

Também com Foucault, no conjunto de sua obra, ficou mais claro que, em questão de saúde pública, trata-se muito mais de proteger a sociedade contra as ameaças individuais, do que o indivíduo contra os males que afetam sua saúde. Como exemplo evidente disso, temos as campanhas de vacinação contra a poliomielite. No meio médico e técnico costuma-se chamar as crianças que recebem a dose da vacina de "soldadinhos", uma vez que essa dose serve menos para proteger a própria criança (o que é comprovado pelo fato de que ela deve tomar a vacina mesmo que já esteja vacinada) 
do que para disseminar através de suas fezes os meios de aniquilação do vírus que causa a doença. Elas são transformadas em soldadinhos na guerra contra a doença.

Toda sociedade constrói os meios de defender-se dos riscos de sua desintegração, seja ela ocasionada por um inimigo humano ou por um inimigo patogênico. Ou ainda, todo governo precisa pensar em estratégias que otimizem os gastos, o que se faz melhor, no tocante à saúde, por meio de uma postura preventiva. A eficácia dessa guerra depende da capacidade do discurso científico de informar sobre o mecanismo da doença e, conseqüentemente, sobre os meios de neutralizá-la. Essa postura "higienista", facilmente inscritível no discurso médico, não o é para a psicanálise. É certo que na história do movimento psicanalítico não faltaram os que tentaram adotá-la. Entre eles, destacam-se Reich, sociologizando a psicanálise, e Bleger, psicologizando-a. As razões que tornam difícil para a psicanálise adotar essa postura não são de ordem moral, valorativa. Já se tentou reduzir a questão a isso, alegando que cabe à psicanálise contemplar mais o sujeito que a sociedade.

O fato é que a noção de doença para a psicanálise não é a mesma para a medicina. Consequientemente, aquilo que se pretende combater e a maneira de fazê-lo variam de um caso para outro. Para a medicina, um sintoma funciona como um "signo", já que indica algo (uma doença) para alguém (o médico). Para a psicanálise, o sintoma também tem essa face sígnica, na medida em que representa algo ao analista, mas define-se também por sua face significante. Ou seja, ele é parte de uma frase à qual a existência de alguém se encontra atrelada. Por isso, Clavreul (1983) afirma que "os signos (sinais) médicos não obedecem às leis da lingüística. Se eles se agrupam, é em síndromes, e não em sintagmas ou paradigmas" (p. 201). Por causa dessa diferença, a posição do psicanalista diante de um sintoma será a de "transformá-lo", ao passo que a do médico será a de "reduzi-lo". É também por essa diferença que uma postura higienista inscreve-se facilmente no discurso médico, e não no psicanalítico.

O conceito de sintoma em psicanálise amplia-se a tal ponto, que só as noções de "demanda" e "transferência" podem impedir um analista de ver sintomas em todo lugar e de maneira arbitrária. Para a psicanálise, o sintoma é sempre um "sintoma analítico", ou seja, inscreve-se no interior da transferência. É porque alguém demanda análise que um sintoma vai ser levado em consideração. Uma postura higienista em psicanálise seria propriamente paranóica, na medida em que, enquanto o discurso médico pode ter mais clareza do que combater, já que escreve com nitidez uma linha demarcatória entre o normal e o patológico, o psicanalista correria o risco de ver sintoma em tudo, inimigos por todo lado.

\section{Dos impasses ao passo}

Aprofundadas algumas das dificuldades de articulação entre o discurso médico e o psicanalítico, resta-nos retomar o que propõe a pesquisa aqui em discussão. Queremos evitar reduzir a questão a um impasse ético, mesmo ressaltando sua importância crucial, fundamentalmente porque se trata de tomar esse impasse como nosso ponto de partida, e não de chegada. Ele está para nós como um instante de ver, e não como um momento de concluir. Isto porque apontar simplesmente um impasse ético, fruto da diferença entre as economias discursivas em jogo, não resolve os impasses do trabalho clínico. Encaminha-os, delimita-os, e com isso abre espaço para algo que resta teorizar, único recurso para escapar de um "puro exercício do poder".

O desafio que se tem pela frente é criar as possibilidades de intersecção entre esses campos sem hierarquizá-los. Quando se trata de duas "línguas" diferentes, o equívoco maior estaria em apostar num "esperanto", língua que não nasce de nenhuma outra, proposta como capaz de eliminar o mal-entendido resultante do conflito entre as línguas. Ou ainda de sucumbir a um "inglês", como língua que acaba impondo-se como universal por questões de hegemonia política. Talvez se trate de apostar em boas condições de tradutibilidade entre as línguas. Tradutibilidade esta capaz de reconhecer que o real delimitado por cada língua implica sempre uma resistência ao traduzível, e que uma língua não pode ser reduzida a outra.

Poderíamos esperar de um tal empreendimento, entre outras coisas, que:

- Num diagnóstico médico, o "psíquico" não aparecesse "por eliminação", como de hábito; não é raro que um médico indique um analista, como eventualmente indicaria um curandeiro ou um benzedor. Mas que um eventual encaminhamento para a análise pudesse ser "propositivo".

- Os psicanalistas pudessem ser mais sensíveis à tarefa de explicitar seus pressupostos e operações de trabalho, de modo que se evidencie melhor sua relação com a prática médica e com aquilo que o médico verifica em sua própria clínica.

\section{Referências}

Almeida Filho, N. (1989). Epidemiologia sem números: Uma introdução crítica à ciência epidemiológica. Rio de Janeiro: Campus.

Brunelle, Y. \& Saucier, A. (1999). Les indicateurs et le système de soins. Québec: Ministère de la Santé et des Services Sociaux.

Clavreul, J. (1983). A ordem médica: poder e impotência do discurso médico. São Paulo: Brasiliense.

Foucault, M. (1994). O nascimento da clínica. Rio de Janeiro: Forense Universitária.

Freud, S. (1980). Psicanálise "silvestre". Em Edição standard brasileira das obras completas de Sigmund Freud Vol. 11 (J. Salomão, Trad.). Rio de Janeiro: Imago, (Trabalho original publicado em 1910)

Garcia, C. (2002). Saber e ciência: psicanálise, saúde pública e saúde mental. Cadernos IPUB, VIII(21), 61-78.

Hanns, L. (2000). Psicoterapias sob suspeita: a psicanálise no século XXI. Em R. A. Pacheco Filho; N. Coelho Júnior \& R. M. Debieux (Orgs.), Ciência, pesquisa, representação e realidade em psicanálise (pp. 175-204). São Paulo: Casa do Psicólogo.

Jerusalinsky, A. (s./d.). Aspectos metodológicos. Documento para fundamentar a "Pesquisa multicêntrica de indicadores de risco para o desenvolvimento infantil". Separata Inédita.

Lacan, J. (1992). O avesso da psicanálise: Seminário XVII. Rio de Janeiro: Jorge Zahar, (Trabalho original publicado em 1969-70)

Mezan, R. (2002). Interfaces da psicanálise. São Paulo: Companhia das Letras. 
Monseny, J. (2001). A ética psicanalítica do diagnóstico. Em A. Quinet (Org.), Psicanálise e psiquiatria: controvérsias e convergências (pp. 69-72). Rio de Janeiro, RJ: Rios Ambiciosos.

Pereira, M. E. C. (2001). O geral das estruturas clínicas e a singularidade do sofrimento: Encontros e desencontros. Em A. Quinet (Org.), Psicanálise e psiquiatria - Controvérsias e convergências (pp. 55-68). Rio de Janeiro: Rios Ambiciosos.

Pommier, G. (1989). Freud apolítico? Porto Alegre: Artes Médicas.

Quinet, A. (2001). A psiquiatria e sua ciência nos discursos da contemporaneidade. Em A. Quinet (Org.), Psicanálise e psiquiatria: controvérsias e convergências (pp. 13-20). Rio de Janeiro: Rios Ambiciosos.
Vieira, M. A. (2001). Dando nome aos bois: Sobre o diagnóstico na psicanálise. Em A. C. Figueiredo(Org.), Psicanálise: pesquisa e clínica (pp. 171-179). Rio de Janeiro: Edições IPUB-CUCA.

Recebido em 10.03.2005

Primeira decisão editorial em 01.11.2005

Versão final em 02.11.2005

Aceito em 05.12.2005 